\title{
Degradation Kinetics of Photoelectrocatalysis on Landfill Leachate Using Codoped $\mathrm{TiO}_{2} / \mathrm{Ti}$ Photoelectrodes
}

\author{
Xiao Zhou, ${ }^{1}$ Yongxin Zheng, ${ }^{1}$ Juan Zhou, ${ }^{1}$ and Shaoqi Zhou ${ }^{1,2,3,4}$ \\ ${ }^{1}$ College of Environment and Energy, South China University of Technology, Guangzhou Higher Education Mega Center, \\ Guangzhou 510006, China \\ ${ }^{2}$ Guizhou Academy of Sciences, Shanxi Road 1, Guiyang 550001, China \\ ${ }^{3}$ State Key Laboratory of Subtropical Building Sciences, South China University of Technology, Guangzhou 510640, China \\ ${ }^{4}$ Key Laboratory of Environmental Protection and Eco-Remediation of Guangdong Regular Higher Education Institutions, \\ South China University of Technology, Guangzhou Higher Education Mega Center, Guangzhou 510641, China \\ Correspondence should be addressed to Shaoqi Zhou; fesqzhou@scut.edu.cn
}

Received 6 December 2014; Revised 4 March 2015; Accepted 12 March 2015

Academic Editor: Ki-Joon Jeon

Copyright (c) 2015 Xiao Zhou et al. This is an open access article distributed under the Creative Commons Attribution License, which permits unrestricted use, distribution, and reproduction in any medium, provided the original work is properly cited.

\begin{abstract}
The photoelectrocatalytic (PEC) oxidation degradation of landfill leachate rejected by reverse osmosis (RO) using a Cu/N codoped $\mathrm{TiO}_{2} / \mathrm{Ti}$ photoelectrode was kinetically investigated in terms of COD concentration. The key factors affecting the reaction rate of PEC oxidation and the removal efficiency of COD concentration were studied, including the COD concentration of landfill leachate, potential bias applied, $\mathrm{pH}$ value of landfill leachate, and the reaction temperature of photoelectrocatalytic reactor. The apparent kinetic model was applied to describe the photoelectrocatalysis reaction. The results showed that the kinetic equation for photoelectrocatalytic oxidation of landfill leachate was fitting well with the experimental data $\left(R_{2}=0.967 \sim 0.998\right)$, with average activation energy $E_{a}=6.35 \times 10^{4} \mathrm{~J} \cdot \mathrm{mol}^{-1}$. It was found that there was an optimal bias voltage of $20 \mathrm{~V}$ and low $\mathrm{pH}$ value was favorable for COD removal in landfill leachate. The reaction order of initial COD concentration (1.326) is higher than that of potential bias (1.102) and $\mathrm{pH}$ value (0.074), which indicates that the reaction rate can be controlled efficiently through adjusted initial concentration. The experiments demonstrated that potential bias would approach its statured value with increasing potential bias.
\end{abstract}

\section{Introduction}

Leachate generated from landfill is heavily loaded wastewater presenting acute and chronic toxicity, which contains various types of organic and inorganic contaminants. Landfill leachate is one of the major environmental problems concerning water pollution $[1,2]$. Different kinds of treatments for landfill leachate have been reported in recent years. Among these treatments, biological methods are typically applied for the treatment of landfill leachate as a result of low cost, prior to its discharge. However, a single biological process has not proven efficient to eliminate the large amount of nonbiodegradable organic substances and the refractory organic pollutants to the required discharge standards $[3,4]$.

Hence, an increasing number of leachate treatment plants have adopted reverse osmosis (RO) technology $[5,6]$.
In recent years, the experimental works [7] have demonstrated the feasibility of using reverse osmosis technology for leachate disposal. In particular, RO can purify both organic and inorganic compounds, and the effluent can meet effluent discharge criteria, but the chemical oxygen demand (COD) and the concentration of organic contaminants are still high in intercepted leachate treated by membranes. The effluent contains a large number of humic substances that inhibited the biomass activity and/or were recalcitrant to biodegradation. Thus, growing interests have been focused on advanced oxidation process (AOP) of landfill leachate as either a post- or pretreatment to improve its biodegradability and treatability $[8,9]$. Photoelectrocatalytic (PEC) process is one of the advanced oxidation process technologies for leachate treatment, which is applying an electrical bias using a $\mathrm{TiO}_{2}$ film electrode. Compared to other semiconductor 
TABLE 1: Average composition of the landfill leachate rejected by RO.

\begin{tabular}{lccccc}
\hline Items & Value & Standard deviation $(\mathrm{SD})$ & Items & Value & Standard deviation $(\mathrm{SD})$ \\
\hline $\mathrm{pH}$ & 7.8 & 0.071 & $\mathrm{BOD}_{5} / \mathrm{COD}$ & 0.01 & 0.0014 \\
$\mathrm{COD}(\mathrm{mg} / \mathrm{L})$ & 4378 & 186.68 & $\mathrm{HS}(\mathrm{mg} / \mathrm{L})$ & 1337.4 & 14.78 \\
DOC $(\mathrm{mg} / \mathrm{L})$ & 2583 & 82.73 & Electrical conductivity $(\mathrm{mS} / \mathrm{cm})$ & 39.2 & 3.11 \\
\hline
\end{tabular}

photocatalysts such as $\mathrm{CdS}, \mathrm{ZnO}$, and $\mathrm{SnO}_{2}$, titanium dioxide $\left(\mathrm{TiO}_{2}\right)$ plays the most important role due to its excellent photostability, relatively low cost, and its ability to photooxidatively destroy most organic pollutants. However, the high recombination rate of photoinduced electron-hole pairs and the low utilization efficiency of visible light are the main factors that generally hold back its application in the wastewater treatment field. $\mathrm{TiO}_{2}$ film electrodes coupled with other semiconductors (such as $\mathrm{CdS}, \mathrm{ZnO}$, and $\mathrm{SnO}_{2}$ ), sensitized with dyes, and doped with metal or nonmetal ions can extend the photoresponse range of $\mathrm{TiO}_{2}$ to visible spectral area and reduce the recombination of photogenerated electron-hole pairs. In particular doping $\mathrm{TiO}_{2}$ film electrodes offer a highly effective way to improve PEC degrading efficiency of recalcitrant organic pollutants. By means of photoelectrocatalytic (PEC) processes, the separation of electron-hole pairs is promoted by electron transfer under the control of an external circuit, significantly enhancing the photocatalytic efficiency. PEC process has been proven to be an efficient method in removing organic contaminants compared with individual electrolysis and photocatalysis process $[10,11]$. At present, PEC process has been widely applied to the degradation of refractory organic pollutants, because the introduction of electrochemical technology into photocatalytic reactions increases the efficiency of processes and it expands the degradation capacity of the recalcitrant organic pollutants $[12,13]$.

In general, the PEC reaction can be described by the Langmuir-Hinshelwood (L-H) kinetic model [14-18]. The PEC degradation of organic pollutants using $\mathrm{TiO}_{2}$ film electrodes is seen to follow the first-order or pseudo-firstorder kinetics [19-23]. However, some groups reported that the PEC degradation of organic pollutants did not fit with pseudo-first-order kinetics. The PC and PEC removal of HA was found to follow zero-order kinetics [24] and PC and PEC TOC removal did not fit zero- or first-order kinetics, owing to a $45 \mathrm{~min}$ lag phase where TOC removals were insignificant. After this lag phase, the TOC removal agreed with the firstorder kinetic model and the first-order rate constant for the PEC process $\left(2.4 \times 10^{2} \mathrm{~min}^{-1}\right)$ was 2.4 times higher than that for the PC process $\left(1.0 \times 10^{2} \mathrm{~min}^{-1}\right)$. The PEC degradation of a mixed dye followed pseudo-first-order kinetics, while the TOC removal proceeded with pseudo-second-order kinetics [25]. The apparent rate constant of pretreated textile effluents was $2.71 \times 10^{2} \mathrm{~min}^{-1}$, while that for raw textile effluents was $2.1 \times 10^{2} \mathrm{~min}^{-1}$ [26]. These results indicate that the photoelectrocatalytic degradation of real organic pollutants is quite complicated, as evidenced by some of the proposed kinetics found in the literature. The dependencies between the organic pollutant concentrations and the PEC reaction rates have been well described. However, the dependencies on other important parameters such as $\mathrm{pH}$, bias potential, light intensity, and additional electrolytes need to be further explored.

In our previous work [27], our research group successfully prepared innovative $\mathrm{Cu} / \mathrm{N}$ codoped $\mathrm{TiO}_{2}$ photoelectrodes by anodising a $\mathrm{Cu} / \mathrm{N}$ codoped $\mathrm{TiO}_{2}$ film on $\mathrm{Ti}$ sheet for PEC degradation of humic acid. This electrode achieved a great degradation of refractory organic pollutants. In this paper, we report an investigation on photoelectrocatalytic treatment of concentrated landfill leachate rejected by reverse osmosis (RO) under various conditions. The COD removal of landfill leachate was used as a model to conduct the PEC oxidation experiments using the $\mathrm{Cu} / \mathrm{N}$ codoped $\mathrm{TiO}_{2}$ photoelectrode. The aim of the study was to determine the photoelectrooxidation efficiency of this $\mathrm{Cu} / \mathrm{N}$ codoped $\mathrm{TiO}_{2}$ photoelectrode for the removal efficiency of landfill leachate at different reaction conditions and the dependencies between the reaction parameters affecting the COD removals (such as initial $\mathrm{pH}$, potential bias, initial temperature, and initial concentration of leachate). The $\mathrm{PEC}$ reaction rates have been quantitatively discussed, to set up a kinetic model to describe the effects of main factors in order to optimise its reaction condition. This study can help to find the optimal conditions for concentrated leachate treatment with photoelectrocatalytic process in a cost-effective way.

\section{Materials and Methods}

2.1. Materials. Concentrated leachate rejected by RO was collected from Guangzhou Domestic Landfill Site $\left(600 \mathrm{~m}^{3} / \mathrm{d}\right)$, South China, where combined process of up-flow anaerobic sludge blanker (UASB), sequencing batch reactor (SBR), continuous microfiltration (CMF), and reverse osmosis (RO) was applied sequentially. The samples were stored in dark at low temperature $\left(4^{\circ} \mathrm{C}\right)$. The average composition of the tested concentrated leachate effluent rejected by $\mathrm{RO}$ is listed in Table 1.

The ratio $\mathrm{BOD}_{5} / \mathrm{COD}$ was about 0.01 , which indicated that the concentrated leachate is difficult to treat biologically. The raw concentrated landfill leachate was prefiltered through a $0.45 \mu \mathrm{m}$ glass fiber filter to remove large particles and debris and maintain uniformity of tested samples.

Graphite electrode was purchased from Guangzhou Jinlong Technology Co., Ltd. The photoelectrocatalytic oxidation was carried out at a constant current using a digital DC power supply. Titanium sheets $(0.2 \mathrm{~mm} \times 50 \mathrm{~mm} \times 50 \mathrm{~mm}$, $99.6 \%$ purity) were polished by metallographic abrasive paper and then degreased by sonicating process in acetone, isopropanol, and methanol. After rinsing with water, the materials were air-dried. Acetone, isopropanol, methanol, $\mathrm{HF}, \mathrm{HNO}_{3}, \mathrm{Cu}\left(\mathrm{NO}_{3}\right)_{2}, \mathrm{NH}_{4} \mathrm{Cl}$, and the above-mentioned 


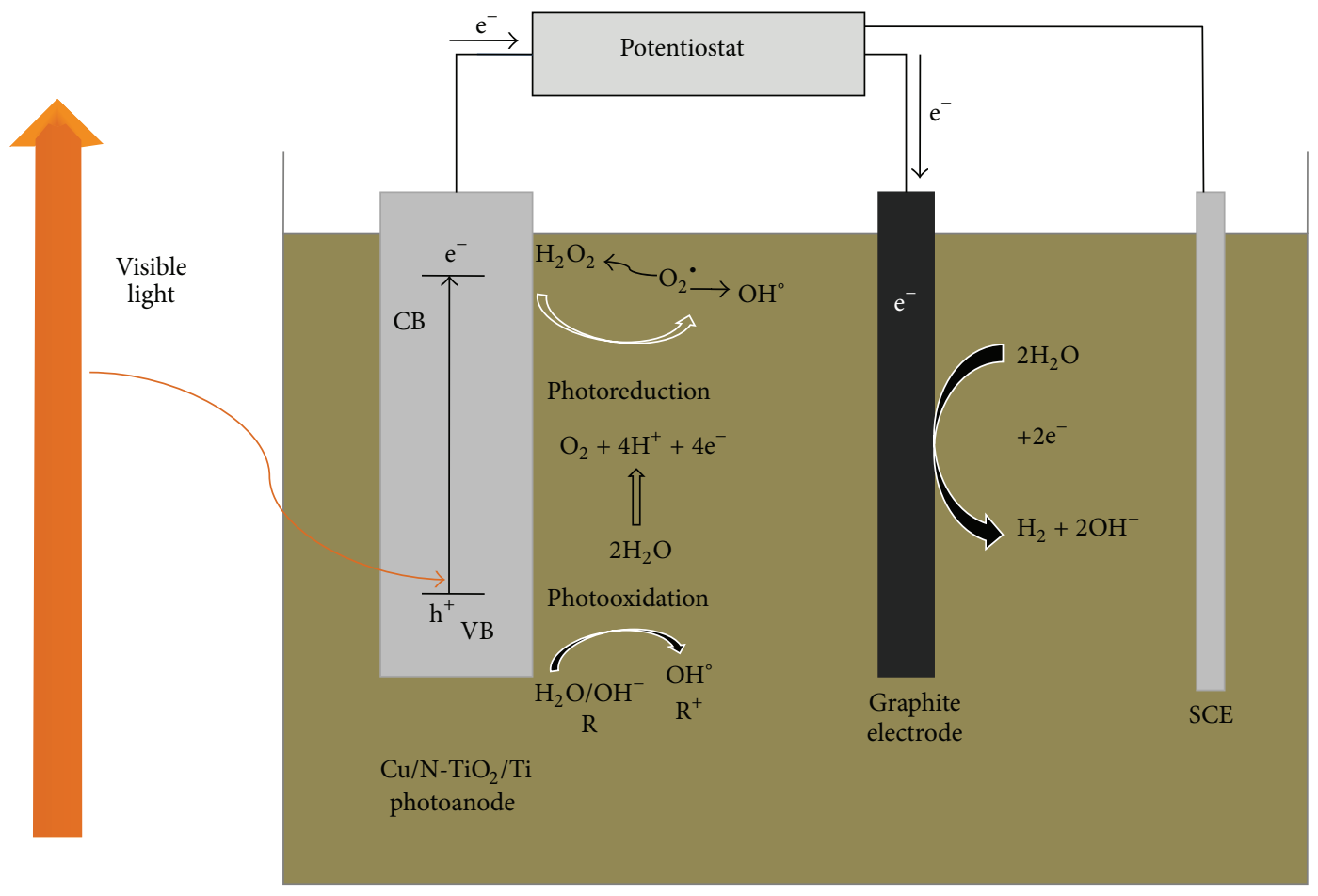

FIGURE 1: Diagram for the reactor system for the photoelectrocatalytic reaction.

chemicals and solvents were of analytical grade and used without further purification.

\subsection{Preparation of $\mathrm{Cu} / \mathrm{N}-\mathrm{TiO}_{2} / \mathrm{Ti}$ Film Electrode. The anodic} oxidation was accomplished with a $33 \mathrm{~V}$ DC power source using titanium sheet as anode and graphite as cathode. The distance between two electrodes was set at $5 \mathrm{~cm}$ in all experiments. The electrolyte contained $0.01 \mathrm{M} \mathrm{HF}$ and $0.1 \mathrm{M}$ $\mathrm{HNO}_{3}$. The anodic oxidation was carried out under $20 \mathrm{~V}$ for $30 \mathrm{~min}$. After electrolysis, titanium sheet was rinsed by water and then air-dried.

The as-prepared $\mathrm{TiO}_{2}$ electrode (on Ti sheet) was used as cathode and graphite as anode. The distance between two electrodes was kept at $5 \mathrm{~cm}$. The electrolyte was a mixture of different volumes of $0.2 \mathrm{M} \mathrm{Cu}\left(\mathrm{NO}_{3}\right)_{2}$ and $0.2 \mathrm{M} \mathrm{NH}_{4} \mathrm{Cl}$, and the molar ratio of $\mathrm{Cu}^{2+} / \mathrm{NH}_{4}{ }^{+}$was adjusted to $1: 1,1: 2$, and $1: 3,2: 1,2: 2$, and $2: 3$, and $3: 1,3: 2$, and $3: 3$, respectively. The entire electrochemical process was performed at $5 \mathrm{~V}$ for $1 \mathrm{~h}$. Finally, the titanium sheet with $\mathrm{Cu} / \mathrm{N}$ codoped $\mathrm{TiO}_{2}$ surface was taken out and rinsed with water and then air-dried.

$\mathrm{Cu} / \mathrm{N}$ codoped $\mathrm{TiO}_{2}$ and nondoped $\mathrm{TiO}_{2}$ electrodes were calcined in air for 2 hours at the temperature of $500^{\circ} \mathrm{C}$. To indicate the ratio of $\mathrm{Cu}^{2+} / \mathrm{NH}_{4}{ }^{+}$in electrolyte and calcination temperature, codoped samples are expressed as the forms of $\mathrm{Cu}_{1} \mathrm{~N}_{1} / \mathrm{TiO}_{2}, \mathrm{Cu}_{1} \mathrm{~N}_{2} / \mathrm{TiO}_{2}, \mathrm{Cu}_{1} \mathrm{~N}_{3} / \mathrm{TiO}_{2}$, and so forth, while pure $\mathrm{TiO}_{2}$ electrodes are expressed as $\mathrm{TiO}_{2}$.

2.3. Analytical Methods. $\mathrm{COD}$ and $\mathrm{BOD}_{5}$ determinations were carried out in duplicate according to the standard methods (APHA, 2005). Chemical oxygen demand (COD) is one of the most commonly used measurable parameters in assessing water quality and an important index for the control of operation of wastewater treatment plants [28, 29]. DOC of the sample solution was measured with Liquid TOC analyzer (Liquid TOC, Germany). $\mathrm{pH}$ of the sample solution was measured with $\mathrm{pH}$ meter (pHS-25C, Jingke Co., Ltd., Shanghai), and the electrical conductivity was analyzed using conductivity meter (DDS-11A, Leici Co., Ltd., Shanghai). Zeta potential of the $\mathrm{Cu} / \mathrm{N}$ codoped $\mathrm{TiO}_{2}$ was measured using a Zeta potential meter (Zetasizer Nano ZS90, Malvern Company, UK).

2.4. Experiments. To evaluate the kinetic model, the effects of initial $\mathrm{pH}$, the voltage, and temperature, as well as the initial leachate concentration, were experimentally explored on the COD removal kinetics. The photoelectrocatalytic process experiment was performed in a batch photoreactor system as shown in Figure 1.

Each test typically began with $500 \mathrm{~mL}$ of concentrated landfill leachate. The photoelectrocatalytic oxidation experiments were conducted in a glass beaker. During these experiments, the photoelectrocatalytic oxidation was carried out at a different current using a digital DC power supply. The plate anode materials were used: $\mathrm{Cu} / \mathrm{N}-\mathrm{TiO}_{2} / \mathrm{Ti}$ film plates and graphite plates using an active anode surface during electrolysis. The electrodes were dipped into the beaker containing $0.6 \mathrm{~L}$ leachates as working volume. A $50 \mathrm{~W}$ tungsten halogen lamp (EXZ MR16 SP, GE, USA) was used as the visible light resource. The light intensity was $80.1 \mathrm{mWcm}^{-2}(380 \mathrm{~nm} \sim 780 \mathrm{~nm})$ measured by SpectraScan 


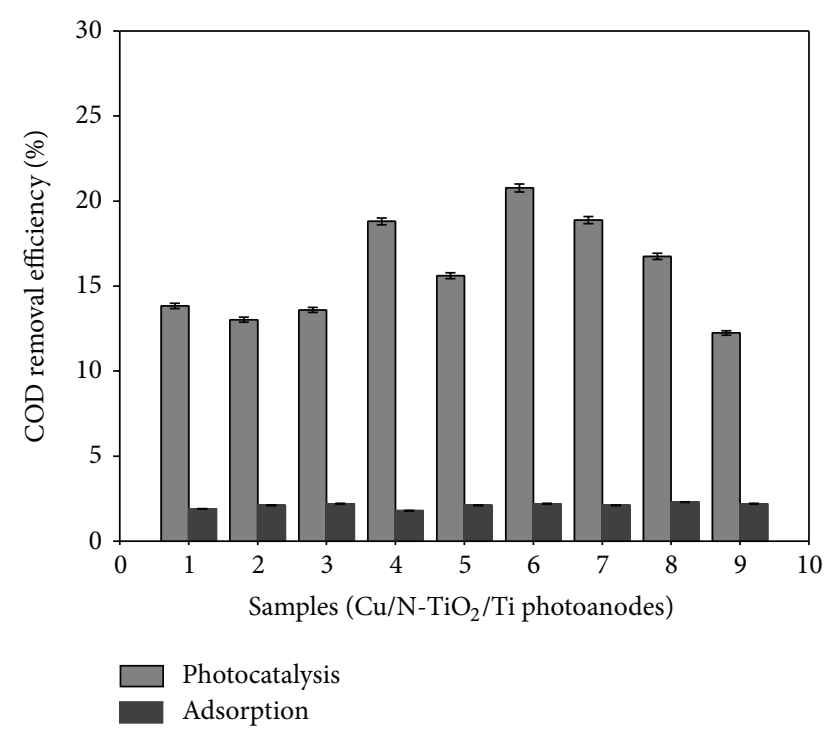

FIGURE 2: The adsorption capacity and visible light photocatalytic (PC) degradation of landfill leachate over the $\mathrm{Cu} / \mathrm{N}-\mathrm{TiO}_{2} / \mathrm{Ti}$ photoanodes.

Spectroradiometers (PR-705, Photo Research, USA). The sample solution was agitated by a magnetic stirrer. Magnetic stirring was kept all along with the reaction at a slow speed.

A constant temperature water bath equipment (HH501, Jingfeng Co., Ltd., Shanghai) controlling the required temperature was used during the reaction. Initial leachate $\mathrm{pH}$ was adjusted to the desired value with concentrated sulfuric acid and sodium hydroxide.

For absorbance measurement, $10 \mathrm{~mL}$ of sample was taken out from the reactor at given time intervals. The solutions were then filtrated with $0.45 \mathrm{~lm}$ glass fiber filter and analyzed COD. All chemicals were at least of analytical grade and used as received, except as noted. Each data point was the mean of two repeated measurements, and standard deviation (SD) was used for descriptive error bars in this study.

\section{Results and Discussion}

3.1. Adsorption Capacity and Photocatalytic Activity of $\mathrm{Cu} / \mathrm{N}$ Codoped $\mathrm{TiO}_{2}$ Photoanodes. Adsorption capacity and visible light photocatalytic (PC) degradation of landfill leachate over the $\mathrm{Cu} / \mathrm{N}-\mathrm{TiO}_{2} / \mathrm{Ti}$ photoanodes, doped with different $\mathrm{Cu}^{2+} / \mathrm{NH}_{4}{ }^{+}$molar ratios codoped $\mathrm{TiO}_{2}$, were evaluated. The test of adsorption capacity was conducted in a dark condition with the $\mathrm{Cu} / \mathrm{N}-\mathrm{TiO}_{2} / \mathrm{Ti}$ electrodes but not connected with the graphite counter electrode. These experiments demonstrated a slight decrease of COD concentration only at the early stage of experiment due to adsorption of leachate by the $\mathrm{Cu} / \mathrm{N}-\mathrm{TiO}_{2} / \mathrm{Ti}$ electrodes. Figure 2 also indicated that all $\mathrm{Cu} / \mathrm{N}$ codoped $\mathrm{TiO}_{2}$ photoanodes have PC activity toward the reduction of $\mathrm{COD}$ concentration. Compared to codoped $\mathrm{TiO}_{2}$ photoanode, the $\mathrm{TiO}_{2}$ electrode was not effective in removing COD, regardless of illumination with high intensity. The removal efficiency increased along with the increased doping copper ion and ammonium ion amounts.

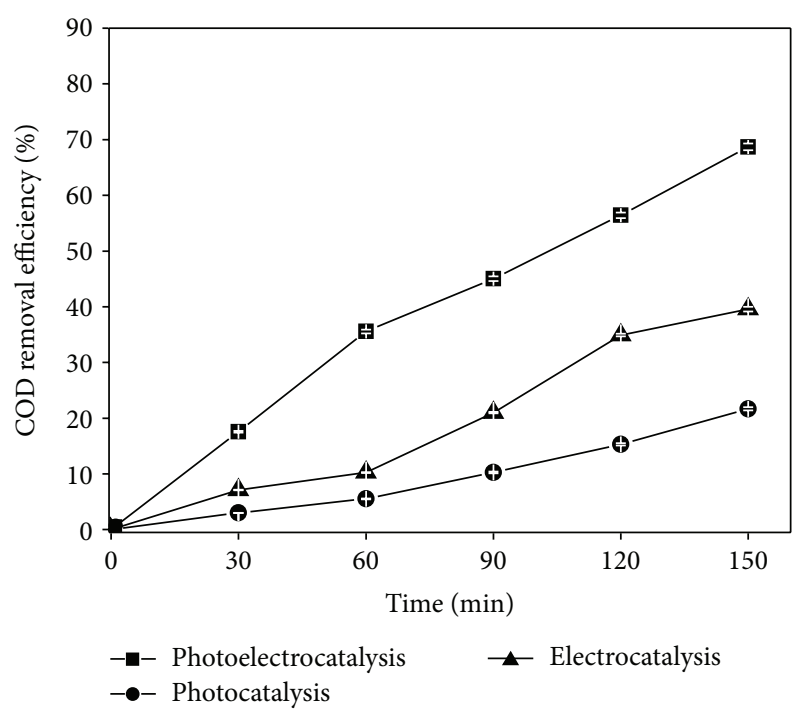

FIgURE 3: Photocatalysis, electrolysis, and photoelectrolysis removal efficiency of landfill leachate on $\mathrm{Cu}_{2} \mathrm{~N}_{3}$ codoped $\mathrm{TiO}_{2}$ electrodes.

The highest performance of photocatalytic was achieved on the $\mathrm{Cu}_{2} \mathrm{~N}_{3}$ codoped $\mathrm{TiO}_{2}$ photoanode (Figure 2). However, the removal efficiency of COD also decreased when the doping copper content exceeded the optimum value $\left(\mathrm{Cu}_{3} \mathrm{~N}_{x}\right)$, which suggested that the photocatalytic activity of $\mathrm{Cu} / \mathrm{N}$ $\mathrm{TiO}_{2} / \mathrm{Ti}$ electrodes decreased. These results demonstrated that the presence of a greater amount of copper was essential to promote the photocatalytic ability. After $150 \mathrm{~min}$ treatment, the $\mathrm{Cu}_{2} \mathrm{~N}_{3}$ codoped $\mathrm{TiO}_{2}$ photoanode shows about 21.7\% PC degradation efficiency when there is only illumination.

Based on our previous work [27], we have successfully prepared $\mathrm{Cu} / \mathrm{N}$ codoped $\mathrm{TiO}_{2}$ electrodes, and we calculated the band gap energies of $\mathrm{Cu}_{1} \mathrm{~N}_{1}, \mathrm{Cu}_{1} \mathrm{~N}_{2}$, and $\mathrm{Cu}_{1} \mathrm{~N}_{3}$ codoped $\mathrm{TiO}_{2}$ are $2.55 \mathrm{eV}, 2.65 \mathrm{eV}$, and $2.90 \mathrm{eV}$, respectively. Because of the reduced band gap energy $\left(E_{g}<3.2 \mathrm{eV}\right)$ in the $\mathrm{Cu} / \mathrm{N}$ codoped $\mathrm{TiO}_{2}$ photoanodes, photogenerated electrons can easily be generated under the illumination. These photogenerated electrons take part in photocatalytic redox reactions. Previous research [30] has shown that the holes react with the electron donors to produce hydroxyl radicals. As the generation of hydroxyl radicals, the organic compounds can be oxidized directly by the hydroxyl radicals or holes on the electrode surface.

3.2. Photocatalysis, Electrolysis, and Photoelectrocatalysis of Landfill Leachate. Photoelectrocatalytic, photocatalytic, and electrocatalytic degradation of landfill leachate in the presence of $\mathrm{Cu} / \mathrm{N}$ codoped $\mathrm{TiO}_{2}$ film electrodes under visible light were evaluated. In Figure 3, compared with the photocatalytic process, the PEC experiment showed greater photocatalytic activity than that of the $\mathrm{PC}$ process. $\mathrm{The}_{2} \mathrm{Cu}_{2} \mathrm{~N}_{3}$ codoped $\mathrm{TiO}_{2}$ electrode achieved COD removal efficiency of $68.7 \%$ in the photoelectrocatalysis at $210 \mathrm{~min}$, while it was only $21.7 \%$ in the photocatalysis. The removal efficiencies of 
the pure photocatalysis and electrocatalysis by the $\mathrm{Cu}_{2} \mathrm{~N}_{3}$ codoped $\mathrm{TiO}_{2}$ electrodes were only $21.7 \%$ and $39.5 \%$, respectively. These results suggested that photoelectrocatalysis had a synergistic interaction with photocatalysis and electrocatalysis. These can be ascribed to the following: the externally applied anodic bias drives away the photogenerated electrons accumulated on $\mathrm{Cu}_{2} \mathrm{~N}_{3}$ codoped $\mathrm{TiO}_{2}$ electrode via the external circuit, reduced the recombination of photogenerated electrons and holes, and promoted the oxidation efficiency of landfill leachate.

These three processes are electric energy driven. Electric energy per mass $\left(E_{\mathrm{EM}}\right)$ can be necessary for describing meaningful energy efficiencies. $E_{\mathrm{EM}}$ is the electric energy in kilowatt hours [kWh] required to bring about the degradation of a unit mass (e.g., one kilogram, $\mathrm{kg}$ ) of contaminant concentrations $[C]$ in polluted water or air. $E_{\mathrm{EM}}$ values [usual units, $\mathrm{kWh} / \mathrm{kg}$ ] can be calculated using the following formula: $E_{\mathrm{EM}}=P t 10^{6} / V\left(\gamma_{i}-\gamma_{f}\right)$ [31]. This figure of merit is most useful when organic concentration $[C]$ is high. $P$ is the rated power $[\mathrm{kW}]$ of the advanced oxidation technologies system, $V$ is the volume [L] of water or air treated in the time $t[\mathrm{~h}]$, and $\gamma_{i}, \gamma_{f}$ are the initial (or influent) and final (or effluent) concentrations $\left[\mathrm{mgL}^{-1}\right]$ of $C$. The results indicated that the electric energy per mass $\left(E_{\mathrm{EM}}\right)$ of pollutant removal of $\mathrm{PC}$, $\mathrm{EC}$, and PEC systems is $60.77,141.58$, and $193.93 \mathrm{kWh} / \mathrm{kg}$, respectively.

\subsection{Photoelectrocatalysis Degradation Reaction Kinetic Model.} Photoelectrocatalytic oxidation is an effective process in treating water and wastewater. However, its reaction process in removing contaminants is very complicated and its formulation is still controversial. In our previous work [32], landfill leachate is a complex wastewater, which contains significant quantities of humic acid, fulvic acid, and small molecule hydrophobic organic pollutants. Contaminants were not completely oxidized during the photoelectrocatalytic reactions but rather transformed to some intermediates with no significant decrease of COD. The accumulation of intermediate and the concentration of hydroxyl radicals varied with the reaction time due to their reaction, which influenced the removal efficiency of COD. The initial rate technique was employed in this study in order to eliminate any interference from competitive reactions from the intermediates formed during photoelectrocatalytic oxidation of landfill leachate. The data which we used average values of several experiments based on COD concentration $\left(\mathrm{COD}_{t}\right)$-time $(t)$. In order to exclude the effect of intermediate products, a polynomial regression model $\left(Y=A+B_{1} X+B_{2} X^{2}+B_{3} X^{3}\right)$ was adopted via Origin 8.5 software, where initial reaction rate $r_{0}$ is obtained by extrapolation of the reaction rate to time $t=0$.

The reaction parameters affecting the $C O D$ removals such as COD concentration, the potential bias applied, $\mathrm{pH}$ value, and the system temperature influence on the relationship between the system $\mathrm{COD}$ concentration $\left(\mathrm{COD}_{t}\right)$ and time $(t)$ have been quantitatively discussed. The third-degree polynomial can perfectly fit the relationship of the system COD concentration and reaction time. The fitting parameters were summarized in Table 2.

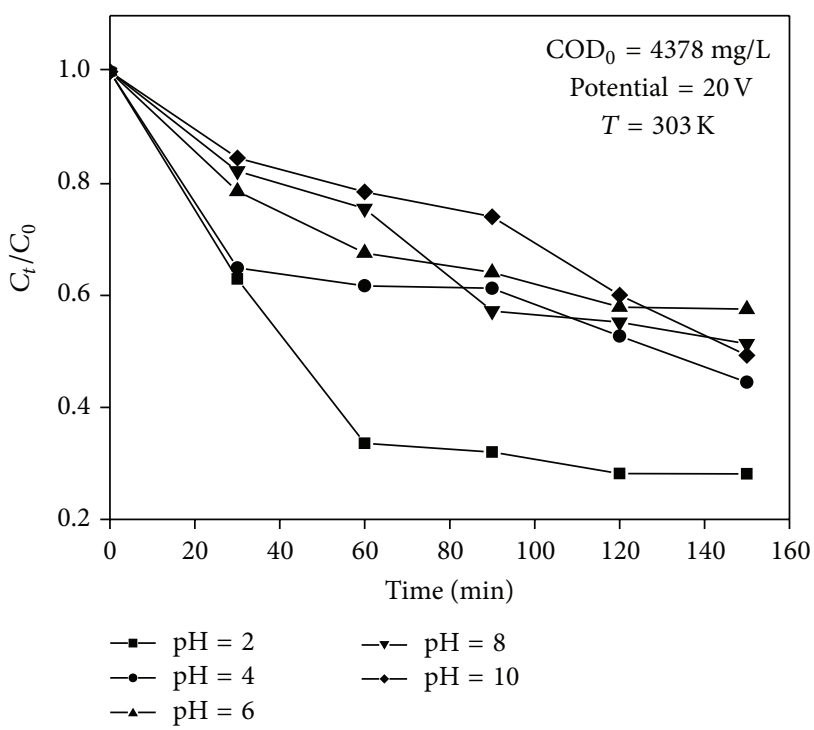

FIGURE 4: The effect of initial $\mathrm{pH}$ on photoelectrocatalysis degradation of landfill leachate.

3.3.1. The Effect of Initial $\mathrm{pH}$. The $\mathrm{pH}$ values of the different wastewater are different, which influences the photoelectrocatalytic reactions for removal of the pollutants. Similarly, $\mathrm{pH}$ plays an important role in the degradation of landfill leachate. To study the effect of initial $\mathrm{pH}$ on the PEC degradation of landfill leachate rejected by $\mathrm{RO}$ treatment, the first set of the tests was carried out with the same light intensity, electrical bias, and initial COD concentration but at different initial $\mathrm{pH}$ values of $2,4,6,8$, and 10 , respectively. The experimental results are shown in Figure 4. The results demonstrated that the COD concentration of landfill leachate decreased much faster in acidic solution than that in the alkaline solution. Li et al. [33] observed similar phenomenon from the electrochemical assisted photocatalytic degradation of humic acid. Many authors [24,34-36] used the point of zero charge $\left(\mathrm{pH}_{\mathrm{pzc}}\right)$ to study the performance of photocatalytic oxidation using $\mathrm{TiO}_{2}$ as photocatalyst. The $\mathrm{TiO}_{2}$ surface is negatively charged when the $\mathrm{pH}$ is higher than the $\mathrm{pH}_{\mathrm{pzc}}$ and an electrostatic repulsion toward anionic compounds dominates. But the surface of $\mathrm{TiO}_{2}$ is positively charged when it is lower. The $\mathrm{pH}$ of the point of zero charge $\left(\mathrm{pH}_{\mathrm{pzc}}\right)$ for $\mathrm{Cu}_{2} \mathrm{~N}_{3}$ codoped $\mathrm{TiO}_{2}$ was 5.58 . The polarity of $\mathrm{TiO}_{2} / \mathrm{Ti}$ electrode surface can be expressed by (2) and (3):

$$
\begin{array}{cc}
\mathrm{pH}<\mathrm{pH}_{\mathrm{pzc}}, \quad \mathrm{TiO}_{2}+\mathrm{H}_{2} \mathrm{O}\left(\mathrm{H}^{+}\right)=\mathrm{TiO}_{2} \mathrm{H}^{+}+\mathrm{H}_{2} \mathrm{O} \\
\mathrm{pH}>\mathrm{pH}_{\mathrm{pzc}}, \quad \mathrm{TiO}_{2}+\mathrm{H}_{2} \mathrm{O}\left(\mathrm{OH}^{-}\right)=\mathrm{TiO}_{2}(\mathrm{H})^{-}+\mathrm{H}_{2} \mathrm{O}
\end{array}
$$

It was reported that the distribution of $\mathrm{TiOH}$ is greater than $80 \%$ when operation $\mathrm{pH}$ value is between 3 and 10 , whereas the distribution of $\mathrm{TiO}^{-}$and $\mathrm{TiOH}_{2}{ }^{+}$is greater than or equal to $20 \%$ for operation $\mathrm{pH}$ value above 10 or below 3 , respectively [37].

Secondly, hydroxyl radicals can be formed by the reaction between hydroxide ions and positive holes. The positive holes are considered as the major oxidation species at low 


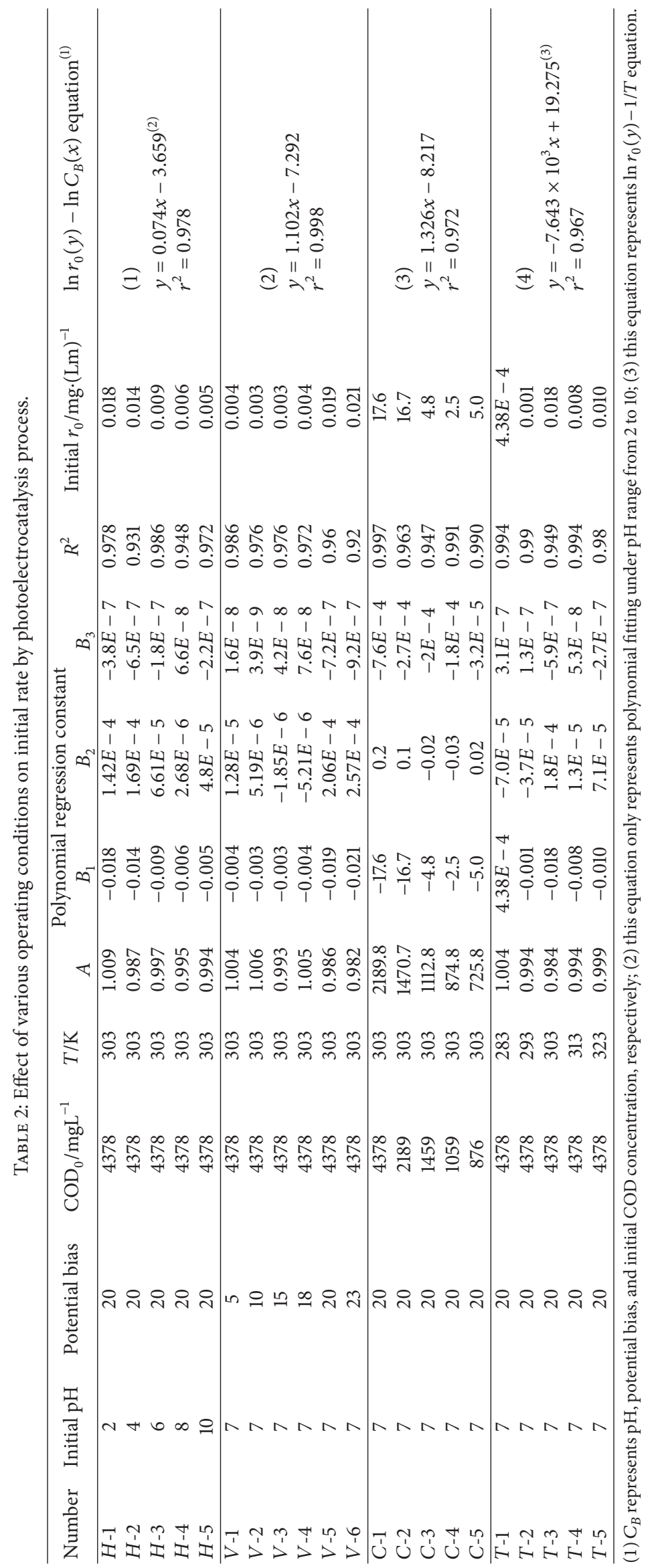




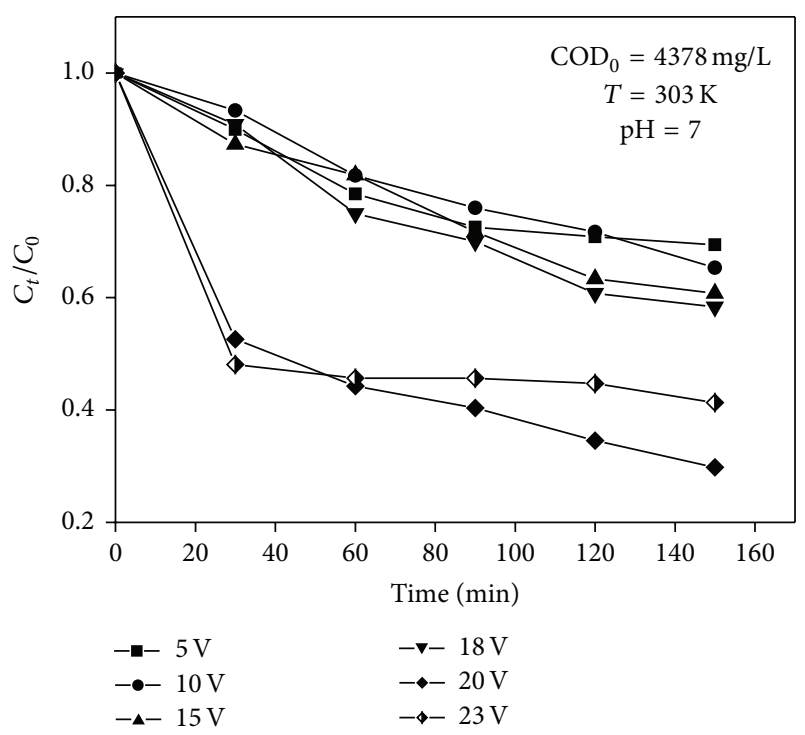

Figure 5: The effect of potential bias on photoelectrocatalysis degradation of landfill leachate.

$\mathrm{pH}$ whereas hydroxyl radicals are considered as the predominant species at neutral or high $\mathrm{pH}$ levels [34]. In the photoelectrocatalytic process, many studies have showed the maximum degradation rate of certain pollutants $[38,39]$ is much faster in an acidic condition than in an alkaline condition. In alkaline solution, the surface of $\mathrm{Cu}_{2} \mathrm{~N}_{3}$ codoped $\mathrm{TiO}_{2}$ electrode is negatively charged and the ionization state of the organic compounds can be changed. There is an electrostatic repulsion between the negative charged surface of the $\mathrm{Cu}_{2} \mathrm{~N}_{3}$ codoped $\mathrm{TiO}_{2}$ electrode and the hydroxide anions. This fact could prevent the formation of hydroxyl radicals and thus decrease the photooxidation.

3.3.2. The Effect of Bias Potential. Bias potential is a key factor to photoelectrocatalytic process efficiency, which draws the photogenerated electrons to the counter electrode. The effect of the bias potential on the PEC degradation rate of landfill leachate was further investigated. Experiments were conducted in a $1000 \mathrm{~mL}$ landfill leachate solution to find an optimum potential. Potential bias ranged from 5 to $+23 \mathrm{~V}$ and COD removal was monitored over 150 minutes. As seen in Figure 5, it is clearly demonstrated that the degradation rate of landfill leachate (as represented by COD removal) was increased as the bias potential increased and reached the largest value at the bias potential of $20 \mathrm{~V}$.

The potential variation from 5 to $20 \mathrm{~V}$ led to an increase of landfill leachate degradation efficiency from $30.6 \%$ to $70.2 \%$. Further increasing of the applied potential has insignificant effect on the degradation. It indicates that the most favorable synergetic effect of the integrated photo- and electrochemical catalysis occurs at the external potential of $20 \mathrm{~V}$. This can be explained by the fact that at the optimal potential bias the electrons and holes are so well separated that further enhancing of the potential bias led to no significant improvement in photoelectrocatalysis activity.

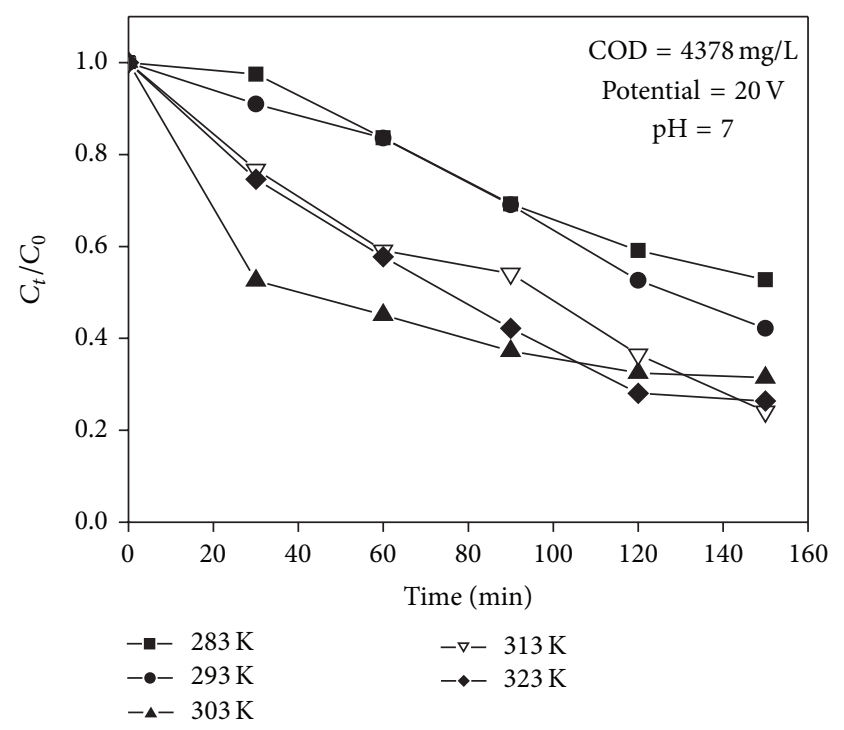

FIGURE 6: The effect of temperature on photoelectrocatalysis degradation of landfill leachate.

The electron transfer in the photocatalytic oxidation process involves two major processes. One is the electron transition in the semiconductor film and the other is the electron injection at the interface (photohole capture). At low potentials the electron transport in the film controls the overall photocatalytic process; as a result, the photocurrent increases with potential. Since for a given compound of given concentration the rate of electron injection or photohole capture (determined by the concentrations of photohole and organic compounds on $\mathrm{TiO}_{2}$ surface) is constant, the photocurrent is saturated with respect to potential bias. Overall, to maintain the progression of reaction at interface, both photoelectrons and photoholes must be removed in time. Otherwise, the build-up of either charge carrier would accelerate the rate of photoelectrons/holes recombination, resulting in a decrease in the overall reaction rate.

3.3.3. The Effect of Temperature. Temperature is one of the important factors influencing photoelectrocatalytic oxidation reaction. A series of experiments were conducted at different working temperatures in the range of $283,293,303,313$ and $323 \mathrm{~K}$, initial $\mathrm{pH}$ of $2,4378 \mathrm{mg} / \mathrm{L}$ of initial COD concentration, and $20 \mathrm{~V}$ of potential bias. The results are shown in Figure 6. As can be seen, temperature has a positive impact on the oxidation degradation rate of landfill leachate. The reaction rate of removal efficiency increases with the increase of temperature. The photoelectrooxidation removal efficiency increased from $47 \%$ to $76 \%$ linearly when the temperature increased up to $313 \mathrm{~K}$. Increasing the temperature from 313 to $323 \mathrm{~K}$ reduced the yield of the process. During $150 \mathrm{~min}$ reaction time, as the reaction temperature rose up from 283 to $303 \mathrm{~K}$, the reaction rate of oxidation increased rapidly from $0.000438 \mathrm{~min}^{-1}$ to $0.018 \mathrm{~min}^{-1}$; then the rate of oxidation increased slowly; this suggested that temperature played an 
important role in photoelectrocatalytic degradation of landfill leachate; the higher the temperature of the reaction system is, the larger the average kinetic energy of the molecular is.

This could explain that increasing temperature had two opposite effects on the reaction yield. On one hand, higher temperature enhanced the generation rate of hydroxyl radicals and therefore enhanced the photoelectrooxidation efficiency of landfill leachate. On the other hand, extremely high temperature over $323 \mathrm{~K}$ started to accelerate the recombination of excited electrons and holes and desorption process of adsorbed reactant species, resulting in decrease of photocatalytic activity. This is in conformity with Arrhenius equation, for which the apparent first-order rate constant $k$ increases linearly with $\exp (-1 / T)[40]$. It is also necessary to take into account that the solubility of oxygen decreases with increasing temperature. Due to its availability in water, adsorbed oxygen may not only serve as the electron acceptor but also be involved in the formation of other oxidative species (superoxide, hydrogen peroxide, and hydroxyl radicals) for preventing of reduction reactions and stabilizing of radical intermediates in photocatalysis [41]. All these reasons drastically reduced the photocatalytic activity when the reaction temperature was greater than $313 \mathrm{~K}$; thus the removal efficiency of landfill leachate declined.

3.3.4. The Effect of Initial Landfill Leachate Concentration. It is important to study the dependence of the photoelectrocatalytic reaction rate on the substrate concentration from both kinetic and application point of view. It is generally noted that the degradation rate increases with the increase in COD concentration to a certain level and a further increase in dye concentration leads to decrease the degradation rate of the COD $[42,43]$. The rate of degradation relates to the probability of ${ }^{\bullet} \mathrm{OH}$ radicals formation on the catalyst surface and to the probability of ${ }^{\bullet} \mathrm{OH}$ radicals reacting with pollutant molecules.

The effects of initial COD concentration on the initial kinetic rate and maximum oxidation removal efficiency were studied by varying the initial concentration of COD from $4378 \mathrm{mg} \mathrm{L}^{-1}$ to $730 \mathrm{mg} \mathrm{L}^{-1}$, under the experiment conditions of initial pH 2.0, potential bias $20 \mathrm{~V}$, and temperature $303 \mathrm{~K}$. The influence of the initial landfill leachate concentration on the photoelectrocatalysis degradation is shown in Figure 7. It can be seen that the initial removal rate and the maximum removal efficiency of COD decrease as the initial concentration of COD increases.

Generally, the degradation rate of organic pollutants decreased with increased concentration. One possible reason is that a relative lower concentration of hydroxyl radical resulting from the increasing COD concentration (same potential bias and $\mathrm{pH}$ ) led to decreasing of the removal efficiency. The degradation rate was enhanced by increasing the concentration to a certain value and then decreased as the concentration continued to increase. The high concentration of the low transparency reduces the light intensity reaching codoped $\mathrm{TiO}_{2} / \mathrm{Ti}$ electrode surface, which leads to a reduction in the hydroxyl radicals generated on the $\mathrm{TiO}_{2}$ surface. There is a large demand for hydroxyl radicals during the

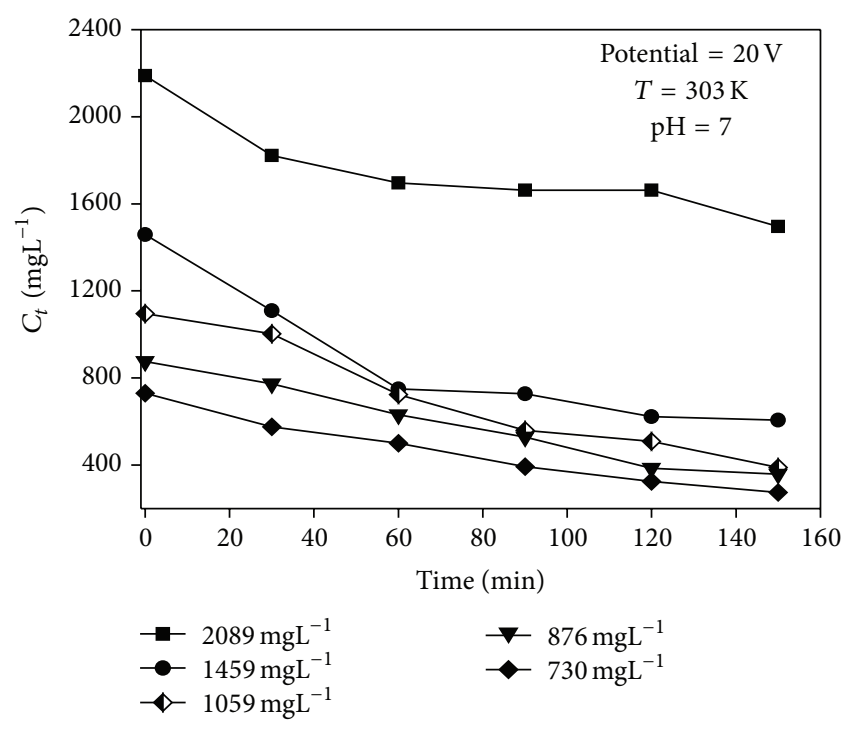

FIGURE 7: The effect of initial concentration on photoelectrocatalysis degradation of landfill leachate.

degradation of high concentration pollutants, but available amount is insufficient.

3.4. Kinetics Modeling. Based on the pseudo-steady-state assumption, at a certain time, the concentration of reactive hydroxyl radicals will not vary with reaction time and its change rate is normally considered to approach zero. The overall photoelectrocatalysis degradation process of landfill leachate could be expressed as

$$
\begin{aligned}
-\frac{d c}{d t} & =k[c]_{0}^{a}=k_{0}[c]_{0}^{a}[V]_{0}^{b}\left[-\log H^{+}\right]_{0}^{c} \\
& =A \exp \left(-\frac{E_{a}}{R T}\right)[c]_{0}^{a}[V]_{0}^{b}\left[-\log H^{+}\right]_{0}^{c} .
\end{aligned}
$$

$k$ is the total oxidation reaction rate constant $\left[\mathrm{L} \cdot(\mathrm{g} \cdot \mathrm{min})^{-1}\right]$, $A$ is preexponential factor $\left[\mathrm{L} \cdot(\mathrm{mol} \cdot \mathrm{min})^{-1}\right], E_{a}$ is apparent reaction activation energy $\left[\mathrm{J} \cdot \mathrm{mol}^{-1}\right], R$ is universal constant $\left[R=8.314 \mathrm{~J} \cdot(\mathrm{mol} \cdot \mathrm{K})^{-1}\right], T$ is temperature $(\mathrm{K}), k_{0}$ is reaction rate which is under a certain temperature, and $a, b, c$ represent reaction partial order of landfill leachate concentration $(c)$, potential bias $(V)$, and $\mathrm{pH}\left(\mathrm{H}^{+}\right)$, respectively.

Based on the double logarithm linear equation in the data of Table 2, the reaction partial order of $c, V$, and $-\log H^{+}$ was $a=1.326, b=1.102$, and $c=0.074$, respectively. Also it can result in straight slope $-7.643 \times 10^{3}$ from $\ln r_{0}(y)-$ $1 / T$ equation, and it represents the value of $-E_{a} / R, E_{a}=$ $63.5 \mathrm{~kJ} \cdot \mathrm{mol}^{-1}$.

Consider the following:

$$
\begin{array}{r}
\ln k_{0}=-\frac{E_{a}}{R} \cdot \frac{1}{T}+\left[b \ln (V)_{0}+c \ln \left(-\log H^{+}\right)+\ln A\right] \\
A=2.61 \times 10^{5} \mathrm{~L} \cdot(\mathrm{mol} \mathrm{min})^{-1} \\
E_{a}=63.5 \mathrm{~kJ} \cdot \mathrm{mol}^{-1} .
\end{array}
$$


It can be eventually expressed as

$$
\begin{aligned}
- & \frac{d c}{d t} \\
= & 2.61 \times 10^{5} \\
& \cdot \exp \left[-\frac{63500}{R T}\right][c]_{0}^{1.326}[V]_{0}^{1.102}\left[-\log H^{+}\right]_{0}^{0.074} .
\end{aligned}
$$

The dynamic model is based on fitting data which came from the initial reaction phase of the experiment, according to the initial reaction stage of the degradation. But for the oxidative degradation process, compared with experimental value, model may be overestimating the initial reaction rate. The low rate ${ }^{\circ} \mathrm{OH}$ of regeneration, precipitation, complexation, and the existence of intermediate hindered the degradation process, these led to alleviate degradation speed. In dynamic equation, the reaction partial of landfill leachate is higher than the bias potential and $\mathrm{pH}$, which shows that the influence of landfill leachate concentration is larger than bias potential during the oxidative degradation process. In addition, in the study of chemical dynamics, activation energy is required to absorb energy for nonactivated molecules turning into activated molecules, which can be measured as the degree of difficulty reaction. The smaller the $E_{a}$, the faster the reaction is carried out. The initial activation energy of photoelectrocatalytic degradation on landfill leachate is $63.5 \mathrm{~kJ} \cdot \mathrm{mol}^{-1}$, meaning the reaction is not difficult to occur.

Since ${ }^{\circ} \mathrm{OH}$ is a highly reactive free radical with an extremely short lifetime of nanoseconds [43], its concentration is normally considered to be constant but at a low level the residual concentration of hydrogen peroxide in the reaction solution depends on its initial concentration and consumption rate. They can be eventually expressed as (3) and (4).

\section{Conclusions}

(1) Concentrated leachate rejected by RO is stable and low biodegradable resulting in environmental issues. In this study, the use of photoelectrocatalytic oxidation process treating concentrated landfill leachate was found to be effective and practicable. Given certain experimental conditions, the removal performances appeared primarily depending on the initial leachate concentrations, bias potential, and initial $\mathrm{pH}$. Either too low or too high values would result in the retardation because the scavenger reaction slowed down the oxidation capability. Under the conditions of $2.0 \mathrm{of} \mathrm{pH}$ value, $20 \mathrm{~V}$ of potential bias applied, and $313 \mathrm{~K}$ of temperature, the removal efficiency of COD was $76.9 \%$.

(2) In this work, for the experiments with different initial $\mathrm{pH}$, bias potential and temperature, and initial leachate concentrations, it was found that the proposed model associated with the two characterized constants had proven useful in quantifying the process to ensure the success of the process. This could be done by simply inputting the two predetermined initial leachate concentration and bias potential, which made photoelectrocatalytic reaction design simpler and more accurate.

(3) The activation energy of $63.5 \mathrm{~kJ} \cdot \mathrm{mol}^{-1}$ indicated that the reaction was not difficult to occur.

\section{Conflict of Interests}

The authors declare that there is no conflict of interests regarding the publication of this paper.

\section{Acknowledgments}

The authors wish to gratefully acknowledge the financial support from the State Ministry of Science and Technology (2008BAE64B05), the National Natural Science Foundation (21277052), the State Key Laboratory of Subtropical Building Science (2011ZB05, 2012ZB06, and 2013ZC03), the Department of Science and Technology of Guangdong Province (2007A032500005), the Department of Guangdong Education and the Science and Technology Bureau (2008A1D0011), and the Environmental Protection Bureau (201203) of China, and they would like to acknowledge assistance from staff who provided full support to this study. Moreover, the authors would like to express their sincere appreciation to the anonymous reviewers for their helpful comments and suggestions.

\section{References}

[1] C. B. Öman and C. Junestedt, "Chemical characterization of landfill leachates-400 parameters and compounds," Waste Management, vol. 28, no. 10, pp. 1876-1891, 2008.

[2] T. Eggen, M. Moeder, and A. Arukwe, "Municipal landfill leachates: a significant source for new and emerging pollutants," Science of the Total Environment, vol. 408, no. 21, pp. 5147-5157, 2010.

[3] R. Rautenbach and R. Mellis, "Waste water treatment by a combination of bioreactor and nanofiltration," Desalination, vol. 95, no. 2, pp. 171-188, 1994.

[4] K. Linde, A.-S. Jönsson, and R. Wimmerstedt, "Treatment of three types of landfill leachate with reverse osmosis," Desalination, vol. 101, no. 1, pp. 21-30, 1995.

[5] A. Chianese, R. Ranauro, and N. Verdone, "Treatment of landfill leachate by reverse osmosis," Water Research, vol. 33, no. 3, pp. 647-652, 1999.

[6] F. Li, K. Wichmann, and W. Heine, "Treatment of the methanogenic landfill leachate with thin open channel reverse osmosis membrane modules," Waste Management, vol. 29, no. 2, pp. 960-964, 2009.

[7] D. L. Nutini and R. N. Kinman, "Use of screw-pressed paper sludge as landfill cover," in Waste Materials in Construction, G. J. Senden, H. A. van der Sloot, J. J. J. M. Goumans, and T. G. Aalbers, Eds., Studies in Environmental Science, pp. 637-642, Elsevier, 1991.

[8] J. J. Wu, C.-C. Wu, H.-W. Ma, and C.-C. Chang, "Treatment of landfill leachate by ozone-based advanced oxidation processes," Chemosphere, vol. 54, no. 7, pp. 997-1003, 2004. 
[9] J. Sun, X. Li, J. Feng, and X. Tian, "Oxone/ $\mathrm{Co}^{2+}$ oxidation as an advanced oxidation process: comparison with traditional Fenton oxidation for treatment of landfill leachate," Water Research, vol. 43, no. 17, pp. 4363-4369, 2009.

[10] X. Zhao, J. Qu, H. Liu et al., "Photoelectrochemical treatment of landfill leachate in a continuous flow reactor," Bioresource Technology, vol. 101, no. 3, pp. 865-869, 2010.

[11] Y. Wu, S. Zhou, X. Ye, D. Chen, K. Zheng, and F. Qin, "Transformation of pollutants in landfill leachate treated by a combined sequence batch reactor, coagulation, Fenton oxidation and biological aerated filter technology," Process Safety and Environmental Protection, vol. 89, no. 2, pp. 112-120, 2011.

[12] F. M. M. Paschoal, M. A. Anderson, and M. V. B. Zanoni, "The photoelectrocatalytic oxidative treatment of textile wastewater containing disperse dyes," Desalination, vol. 249, no. 3, pp. 13501355, 2009.

[13] J. Bai, Y. Liu, J. Li, B. Zhou, Q. Zheng, and W. Cai, "A novel thinlayer photoelectrocatalytic (PEC) reactor with double-faced titania nanotube arrays electrode for effective degradation of tetracycline," Applied Catalysis B: Environmental, vol. 98, no. 34, pp. 154-160, 2010.

[14] X.-L. Yan, H.-X. Shi, and D.-H. Wang, "Photoelectrocatalytic degradation of phenol using a $\mathrm{TiO}_{2} / \mathrm{Ni}$ thin-film electrode," Korean Journal of Chemical Engineering, vol. 20, no. 4, pp. 679684, 2003.

[15] N. K. Kuromoto, R. A. Simão, and G. A. Soares, "Titanium oxide films produced on commercially pure titanium by anodic oxidation with different voltages," Materials Characterization, vol. 58, no. 2, pp. 114-121, 2007.

[16] B. S. Flavel, J. Yu, J. G. Shapter, and J. S. Quinton, "Electrochemical characterisation of patterned carbon nanotube electrodes on silane modified silicon," Electrochimica Acta, vol. 53, no. 18, pp. 5653-5659, 2008.

[17] J.-H. Chang, A. V. Ellis, Y.-H. Hsieh, C.-H. Tung, and S.-Y. Shen, "Electrocatalytic characterization and dye degradation of Nano$\mathrm{TiO}_{2}$ electrode films fabricated by CVD," Science of the Total Environment, vol. 407, no. 22, pp. 5914-5920, 2009.

[18] K. Esquivel, L. G. Arriaga, F. J. Rodríguez, L. Martínez, and L. A. Godínez, "Development of a $\mathrm{TiO}_{2}$ modified optical fiber electrode and its incorporation into a photoelectrochemical reactor for wastewater treatment," Water Research, vol. 43, no. 14, pp. 3593-3603, 2009.

[19] M. Zhou and X. Ma, "Efficient photoelectrocatalytic activity of $\mathrm{TiO}_{2} / \mathrm{Ti}$ anode fabricated by metalorganic chemical vapor deposition (MOCVD)," Electrochemistry Communications, vol. 11, no. 4, pp. 921-924, 2009.

[20] Z. Zhang, Y. Yuan, G. Shi et al., "Photoelectrocatalytic activity of highly ordered $\mathrm{TiO}_{2}$ nanotube arrays electrode for azo dye degradation," Environmental Science \& Technology, vol. 41, no. 17, pp. 6259-6263, 2007.

[21] Y. B. Xie, "Photoelectrochemical application of nanotubular titania photoanode," Electrochimica Acta, vol. 51, no. 17, pp. 3399-3406, 2006.

[22] Y. Su, S. Chen, X. Quan, H. Zhao, and Y. Zhang, "A silicondoped $\mathrm{TiO}_{2}$ nanotube arrays electrode with enhanced photoelectrocatalytic activity," Applied Surface Science, vol. 255, no. 5, pp. 2167-2172, 2008.

[23] X. Quan, S. G. Yang, X. L. Ruan, and H. M. Zhao, "Preparation of titania nanotubes and their environmental applications as electrode," Environmental Science \& Technology, vol. 39, no. 10, pp. 3770-3775, 2005.
[24] H. Selcuk and M. Bekbolet, "Photocatalytic and photoelectrocatalytic humic acid removal and selectivity of $\mathrm{TiO}_{2}$ coated photoanode," Chemosphere, vol. 73, no. 5, pp. 854-858, 2008.

[25] Z. Zainal, C. Y. Lee, M. Z. Hussein, A. Kassim, and N. A. Yusof, "Electrochemical-assisted photodegradation of mixed dye and textile effluents using $\mathrm{TiO}^{2}$ thin films," Journal of Hazardous Materials, vol. 146, no. 1-2, pp. 73-80, 2007.

[26] Z. Zainal, C. Y. Lee, M. Z. Hussein, A. Kassim, and N. A. Yusof, "Electrochemical-assisted photodegradation of dye on $\mathrm{TiO}_{2}$ thin films: investigation on the effect of operational parameters," Journal of Hazardous Materials, vol. 118, no. 1-3, pp. 197-203, 2005.

[27] X. Zhou, Y. Zheng, D. Liu, and S. Zhou, "Photoelectrocatalytic degradation of humic acids using codoped $\mathrm{TiO}_{2}$ film electrodes under visible light," International Journal of Photoenergy, vol. 2014, Article ID 356365, 10 pages, 2014.

[28] D. Brdjanovic, M. C. M. van Loosdrecht, P. Versteeg, C. M. Hooijmans, G. J. Alaerts, and J. J. Heijnen, "Modeling COD, N and P removal in a full-scale wwtp Haarlem Waarderpolder," Water Research, vol. 34, no. 3, pp. 846-858, 2000.

[29] D.-W. Liang, T. Zhang, and H. H. P. Fang, "Anaerobic degradation of dimethyl phthalate in wastewater in a UASB reactor," Water Research, vol. 41, no. 13, pp. 2879-2884, 2007.

[30] J. Yang, J. Dai, C. Chen, and J. Zhao, "Effects of hydroxyl radicals and oxygen species on the 4-chlorophenol degradation by photoelectrocatalytic reactions with $\mathrm{TiO}_{2}$-film electrodes," Journal of Photochemistry and Photobiology A: Chemistry, vol. 208, no. 1, pp. 66-77, 2009.

[31] J. R. Bolton, K. G. Bircher, W. Tumas, and C. A. Tolman, "Figures-of-merit for the technical development and application of advanced oxidation technologies for both electric- and solar-driven systems-(IUPAC Technical Report)," Pure and Applied Chemistry, vol. 73, no. 4, pp. 627-637, 2001.

[32] Y. Wu, S. Zhou, K. Zheng, X. Ye, and F. Qin, "Mathematical model analysis of Fenton oxidation of landfill leachate," Waste Management, vol. 31, no. 3, pp. 468-474, 2011.

[33] X. Z. Li, F. B. Li, C. M. Fan, and Y. P. Sun, "Photoelectrocatalytic degradation of humic acid in aqueous solution using a $\mathrm{Ti} / \mathrm{TiO}_{2}$ mesh photoelectrode," Water Research, vol. 36, no. 9, pp. 22152224, 2002.

[34] I. K. Konstantinou and T. A. Albanis, "TiO2-assisted photocatalytic degradation of azo dyes in aqueous solution: kinetic and mechanistic investigations: a review," Applied Catalysis B: Environmental, vol. 49, no. 1, pp. 1-14, 2004.

[35] I. Poulios and I. Tsachpinis, "Photodegradation of the textile dye reactive black 5 in the presence of semiconducting oxides," Journal of Chemical Technology and Biotechnology, vol. 74, no. 4, pp. 349-357, 1999.

[36] M. N. Chong, B. Jin, C. W. K. Chow, and C. Saint, "Recent developments in photocatalytic water treatment technology: a review," Water Research, vol. 44, no. 10, pp. 2997-3027, 2010.

[37] X. Quan, X. Ruan, H. Zhao, S. Chen, and Y. Zhao, "Photoelectrocatalytic degradation of pentachlorophenol in aqueous solution using a $\mathrm{TiO}_{2}$ nanotube film electrode," Environmental Pollution, vol. 147, no. 2, pp. 409-414, 2007.

[38] P. A. Carneiro, D. P. Oliveira, G. A. Umbuzeiro, and M. V. B. Zanoni, "Mutagenic activity removal of selected disperse dye by photoeletrocatalytic treatment," Journal of Applied Electrochemistry, vol. 40, no. 3, pp. 485-492, 2010. 
[39] U. I. Gaya and A. H. Abdullah, "Heterogeneous photocatalytic degradation of organic contaminants over titanium dioxide: a review of fundamentals, progress and problems," Journal of Photochemistry and Photobiology C: Photochemistry Reviews, vol. 9, no. 1, pp. 1-12, 2008.

[40] S. Malato, P. Fernández-Ibáñez, M. I. Maldonado, J. Blanco, and W. Gernjak, "Decontamination and disinfection of water by solar photocatalysis: recent overview and trends," Catalysis Today, vol. 147, no. 1, pp. 1-59, 2009.

[41] M. Saquib and M. Muneer, " $\mathrm{TiO}_{2}$-mediated photocatalytic degradation of a triphenylmethane dye (gentian violet), in aqueous suspensions," Dyes and Pigments, vol. 56, no. 1, pp. 3749, 2003.

[42] S. Sakthivel, B. Neppolian, M. V. Shankar, B. Arabindoo, M. Palanichamy, and V. Murugesan, "Solar photocatalytic degradation of azo dye: comparison of photocatalytic efficiency of $\mathrm{ZnO}$ and $\mathrm{TiO}_{2}$," Solar Energy Materials and Solar Cells, vol. 77, no. 1, pp. 65-82, 2003.

[43] A. Danion, J. Disdier, C. Guillard, F. Abdelmalek, and N. Jaffrezic-Renault, "Characterization and study of a single- $\mathrm{TiO}_{2}$ coated optical fiber reactor," Applied Catalysis B: Environmental, vol. 52, no. 3, pp. 213-223, 2004. 

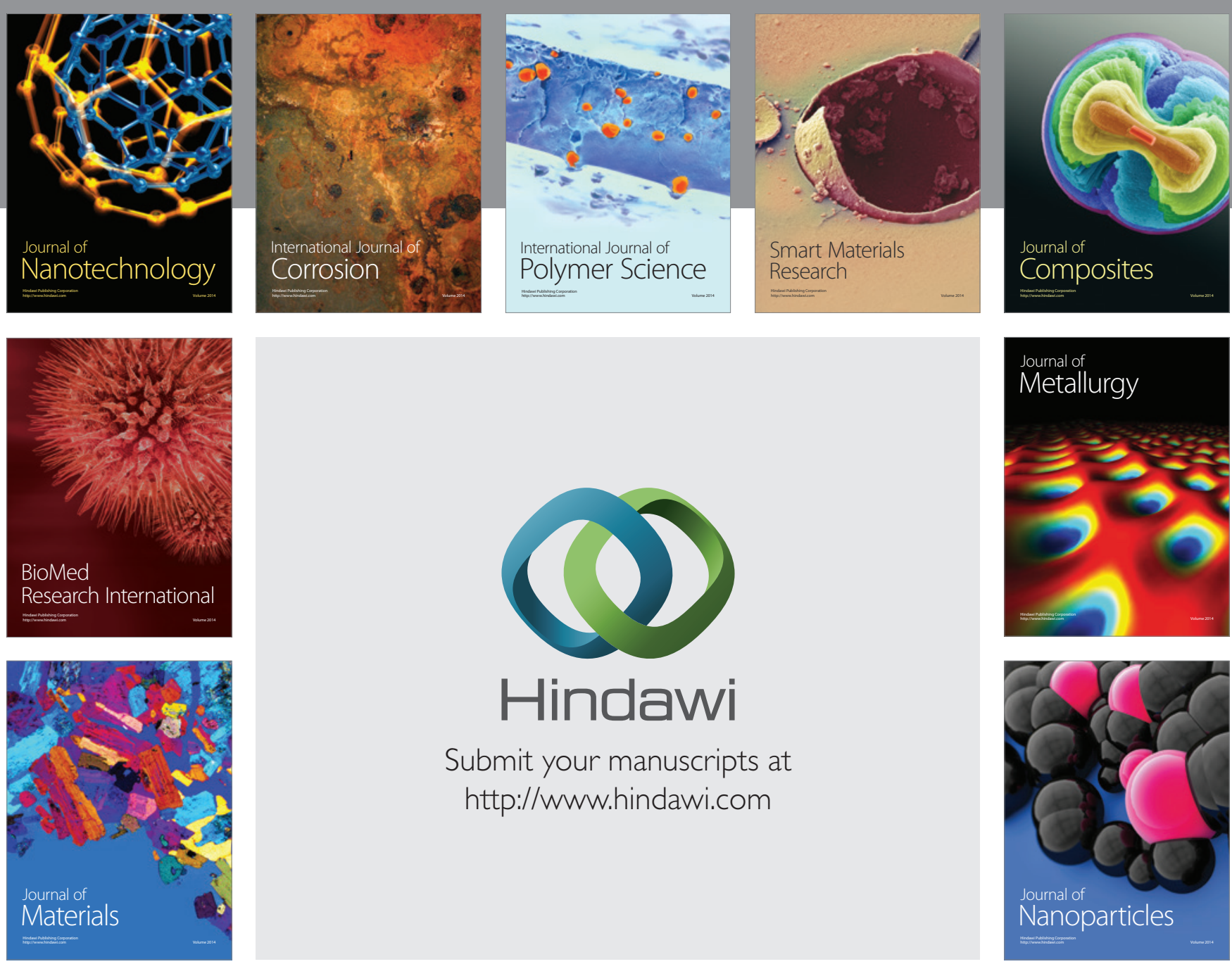

Submit your manuscripts at http://www.hindawi.com
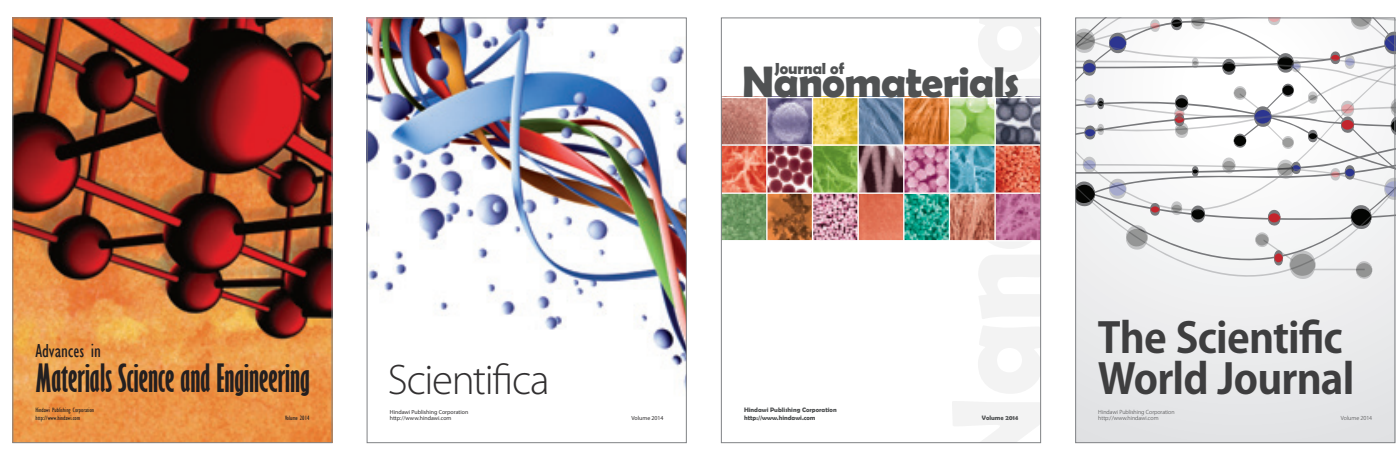

\section{The Scientific World Journal}
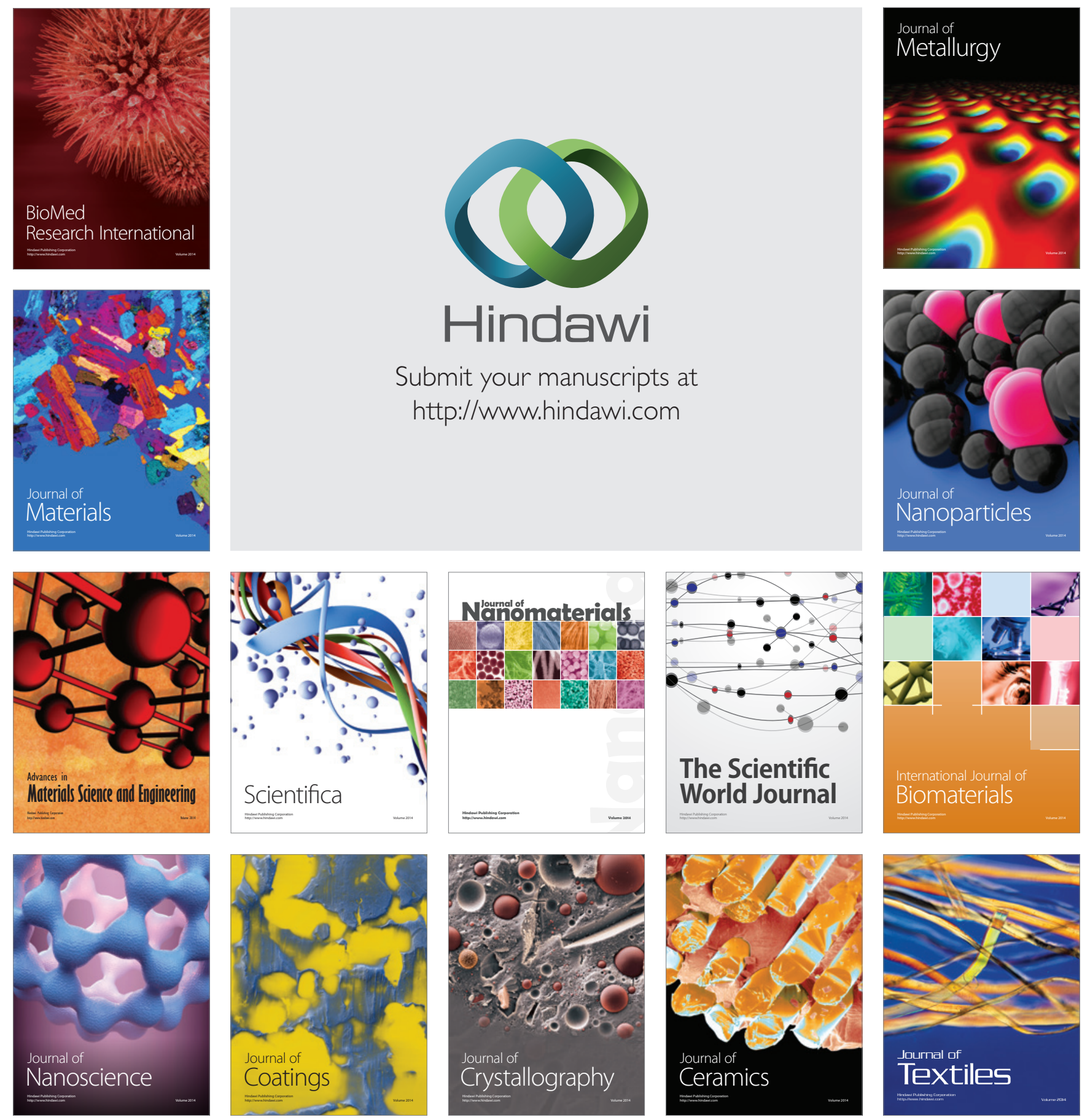